\title{
Bioconversion to Raspberry Ketone is Achieved by Several Non-related Plant Cell Cultures
}

\author{
Suvi T. Häkkinen, Tuulikki Seppänen-Laakso, Kirsi-Marja Oksman-Caldentey and \\ Heiko Rischer* \\ VTT Technical Research Centre of Finland Ltd., Espoo, Finland
}

Bioconversion, i.e., the use of biological systems to perform chemical changes in synthetic or natural compounds in mild conditions, is an attractive tool for the production of novel active or high-value compounds. Plant cells exhibit a vast biochemical potential, being able to transform a range of substances, including pharmaceutical ingredients and industrial by-products, via enzymatic processes. The use of plant cell cultures offers possibilities for contained and optimized production processes which can be applied in industrial scale. Raspberry ketone [4-(4-hydroxyphenyl)butan-2-one] is among the most

OPEN ACCESS

Edited by: Rosella Franconi,

Italian National Agency for New Technologies, Energy and Sustainable Economic Development, Italy

Reviewed by: Biswapriya Biswavas Misra, University of Florida, USA Doriana Triggiani,

Italian National Agency for New Technologies, Energy and Sustainable Economic Development, Italy

*Correspondence: Heiko Rischer heiko.rischer@vtt.fi

Specialty section: This article was submitted to Plant Biotechnology, a section of the journal Frontiers in Plant Science

Received: 16 September 2015 Accepted: 06 November 2015 Published: 24 November 2015

Citation:

Häkkinen ST, Seppänen-Laakso T, Oksman-Caldentey K-M and Rischer H (2015) Bioconversion to Raspberry Ketone is Achieved by Several Non-related Plant Cell

Cultures. Front. Plant Sci. 6:1035.

doi: 10.3389/fpls.2015.01035 interesting natural flavor compounds, due to its high demand and significant market value. The biosynthesis of this industrially relevant flavor compound is relatively well characterized, involving the condensation of 4-coumaryl-CoA and malonyl-CoA by Type III polyketide synthase to form a diketide, and the subsequent reduction catalyzed by an NADPH-dependent reductase. Raspberry ketone has been successfully produced by bioconversion using different hosts and precursors to establish more efficient and economical processes. In this work, we studied the effect of overexpressed RiZS1 in tobacco on precursor bioconversion to raspberry ketone. In addition, various wild type plant cell cultures were studied for their capacity to carry out the bioconversion to raspberry ketone using either 4-hydroxybenzalacetone or betuligenol as a substrate. Apparently plant cells possess rather widely distributed reductase activity capable of performing the bioconversion to raspberry ketone using cheap and readily available precursors.

\section{Keywords: betuligenol, bioconversion, 4-hydroxybenzalacetone, plant cell culture, raspberry ketone}

\section{INTRODUCTION}

The characteristic aroma component in raspberry (Rubus idaeus) fruits is 4-(4-hydroxyphenyl) butan-2-one, also called raspberry ketone or frambinone (Feron et al., 2007). The amount of raspberry ketone in raspberry fruits is only around $1-4 \mathrm{mg} / \mathrm{kg}$ fruits. Raspberry ketone is one of the most expensive flavor compounds. Natural raspberry ketone flavor ranks second behind natural vanillin, with a total potential market value between 6 and 10 million euros (Feron and Wache, 2005), although currently the commercial demand cannot be satisfied. The EC Flavor Directive $(88 / 388 / \mathrm{EEC})$ defines natural flavors as 'flavoring substances or preparations which are obtained by appropriate physical processes or enzymatic or microbiological processes from material of vegetal or animal origin.' Natural flavors include products obtained through microbial or enzymatic processes as long as the precursor/raw material is natural and obtained via physical or 
bio-processes and the precursor and product can be found in nature or as components of traditional foods. Products that occur in nature but are produced via a chemical (non-biological) process are called 'nature-identical'; this mode of production is no longer accepted as consumer-friendly (Vandamme and Soetaert, 2007). In addition to traditional flavoring applications, raspberry ketone has attracted wide interest in the so-called cosmaceutical industry, for its skin-lightening and weight-loss properties (Morimoto et al., 2005; Park, 2010; Lin et al., 2011).

The biosynthesis of this industrially sought-after flavor compound is a comparatively well characterized diketide pathway, involving the condensation of 4-coumaryl-CoA and malonyl-CoA. First coumaroyl-CoA and malonyl-CoA form $p$-hydroxybenzalacetone (4-OHBA) in a decarboxylative condensation catalyzed by a Type III polyketide synthase called benzalacetone synthase (BAS) (Abe et al., 2001). Several candidate polyketide synthases from Rubus have been identified (RiPKS1-5), and among those RiPKS4 exhibits a specific C-terminal sequence which is different from the usually conserved region in chalcone synthases (CHSs) (Zheng et al., 2001; Zheng and Hrazdina, 2008). RiPKS4 has both BAS and CHS activity in vitro, and therefore selective blocking of the CHS activity of RiPKS4 would be difficult to achieve. Instead it seems very likely that the reaction toward benzalacetone (and further to raspberry ketone) is determined by precursor availability and especially the interaction with a specific reductase. Koeduka et al. (2011) identified an $\mathrm{NADPH}$-dependent reductase from raspberry, called raspberry ketone/zingerone synthase 1 (RiZS1), which was suggested to be responsible for the last step in raspberry ketone biosynthesis. However, this gene has not hitherto been functionally tested in planta.

Plant cell cultures have been studied as useful agents for various biotransformation reactions of organic compounds, including oxidation, reduction, hydroxylation, esterification, methylation, isomerization, hydrolysis and glycosylation (Giri et al., 2001; Ishihara et al., 2003). Raspberry ketone has been produced via bioconversion with different hosts including bacteria, yeast and plant cells, using e.g., p-coumaric acid, benzoic acid, benzaldehyde, 4-OHBA (1) or betuligenol (or rhododendrol) (2) as a precursor (Figure 1) (Fischer et al., 2001; Beekwilder et al., 2007).

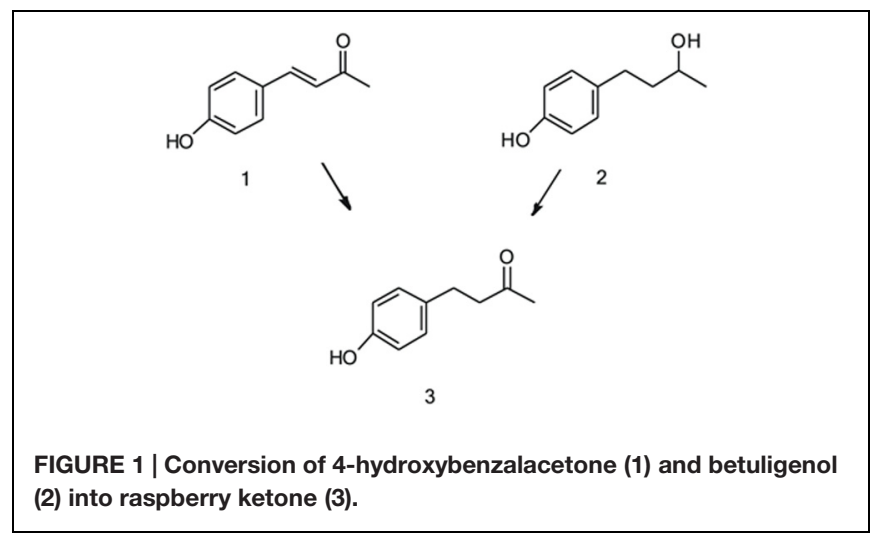

The berry-derived precursor $\mathbf{1}$ is not abundant in nature, but it can be produced by bacterial cultivation via condensation of hydroxybenzaldehyde and acetone (Feron et al., 2007). 2 is a secondary alcohol isolated originally from Taxus wallichiana (Chattopadhyay et al., 2001). It is also found, in e.g., birch bark, rhododendron, alder, maple and fir, mainly in its glycosylated form called betuloside. Betuloside can be converted into betuligenol, by e.g., microbial $\beta$-glucosidase (Dumont et al., 1996). Bioconversion of 2 into 3 has been successfully achieved by various microbial cells (Dumont et al., 1996; Kosjek et al., 2003) and Atropa belladonna hairy roots (Srivastava et al., 2013). In a study by Kosjek et al. (2003), the oxidation reaction from $\mathbf{2}$ to $\mathbf{3}$ was performed in the actinomycete Rhodococcus by using acetone as a hydrogen acceptor. However, when A. belladonna hairy roots were fed with 2 , both 3 and betuloside were formed without the requirement of an additional co-substrate. On the other hand, Fujita et al. (1998) showed that callus cultures of Acer nikoence (Nikko maple) converted fed $\mathbf{3}$ to $\mathbf{2}$ and their glycosides. Interestingly, $\mathbf{3}$ was only found in the culture medium, whereas glycosides were present in the intracellular space. The authors suggested that a certain specific alcohol dehydrogenase $(\mathrm{ADH})$ and a glycosyltransferase participate in these reactions. Bioconversion of 1 was accomplished with various microbial cells, yielding raspberry ketone with varying conversion efficiencies (Fuganti and Zucchi, 1998). They observed that with longer incubation times, conversion of $\mathbf{1}-\mathbf{3}$ continued to formation of $\mathbf{2}$. It is known that a reaction from $\mathbf{1}$ to $\mathbf{3}$ is catalyzed by an NADPH-dependent enzyme, which was characterized from Rubus idaeus by Koeduka et al. (2011). On the other hand, the conversion step from 2 to 3 has not yet been characterized. Indeed, Beekwilder et al. (2007) showed that Escherichia coli possesses an endogenous reductase activity to convert $\mathbf{1}$ into $\mathbf{3}$, after $p$-coumaric acid feeding to the cells expressing BAS. It is thus likely that the reductase activity required for this conversion is rather widely distributed in nature. In this study we present bioconversion studies related to raspberry ketone, performed with various plant cell cultures derived from plant species unrelated to raspberry.

\section{MATERIALS AND METHODS}

\section{Plant Material and Precursors}

Hairy roots of Nicotiana tabacum SR1 'Petite Havana' (tobacco, VTT Culture Collection no. VTTCC P-120068, Supplementary Figure S3) and Catharanthus roseus (Madagascar periwinkle, VTTCC P-120070) as well as $N$. tabacum cell suspension cultures SR1 (VTTCC P-120003) and BY-2 (VTTCC P-120001) were initiated and maintained as described by Häkkinen et al. (2012). Hairy roots of Hyoscyamus muticus (Egyptian henbane, VTTCC P-120039, Supplementary Figure S4) were initiated and maintained as described in Häkkinen et al. (2005). Hordeum vulgare 'Pokko' cell suspension culture (barley, VTTCC P-120080) was established and maintained as described in Ritala et al. (1993). Rubus idaeus (raspberry, VTTCC P120090), Rubus chamaemorus (cloudberry, VTTCC P-120083, Supplementary Figure S2) and Rubus arcticus (arctic bramble, 
VTTCC P120089) were maintained as described in Nohynek et al. (2014) with slight modifications (Supplementary Figure S5). Vaccinium myrtillus (bilberry, VTTCC P-120045) cell suspension was maintained in modified McCown Woody Plant medium (McCown and Lloyd, 1981). Plumbago auriculata (leadwort, VTTCC P-120006) cell suspension culture was maintained in modified Murashige and Skoog's medium (Murashige and Skoog, 1962). N. benthamiana was cultivated according to Joensuu et al. (2010). Precursors p-hydroxybenzalacetone (4-OHBA) and betuligenol (rhododendrol) were purchased from Sigma-Aldrich (S350656, USA) and TCI America (R0121, USA), respectively. Raspberry ketone was obtained from Sigma-Aldrich (W258806, USA).

\section{RiZS1 Plant Vector Construct}

Rubus idaeus ketone/zingerone synthase 1 (RiZS1) with NCBI Accession no. JN166691.1 was ordered from GenScript USA Inc. (USA) and cloned into the Gateway ${ }^{\circledR}$ plant compatible vector pK2GW7 (Life Technologies ${ }^{\mathrm{TM}}$ ) according to manufacturer instructions. The resulting vector carrying 35S-RiZS1 was transformed into Agrobacterium rhizogenes LBA9402 and A. tumefaciens LBA4404 by electroporation. The presence of the transgene was confirmed by PCR using Gateway ${ }^{\circledR}$ primers 5'-GGGGACAAGTTTGTACAAAAAAGCAGGC-3' and $3^{\prime}$-GGGGACCACTTTGTACAAGAAAGCTGGG-5' for amplification of the vector region between ATTB1 and ATTB2 sites.

\section{Transient Expression in $\mathbf{N}$. benthamiana}

The Agrobacterium suspensions were infiltrated into the leaves of 6-week-old $N$. benthamiana plants as described previously (Joensuu et al., 2010). Briefly, N. benthamiana plants were cultivated in a greenhouse for 6 weeks before infiltration. One day prior to infiltration a bacterial suspension was inoculated and incubated at $+28^{\circ} \mathrm{C}$ overnight. The cultures were diluted to $\mathrm{OD}_{600} 0.35$ with $10 \mathrm{mM} \mathrm{MgSO} 4,10 \mathrm{mM}$ MES buffer. Bufferinfiltrated leaves were used as control. LBA4404 carrying p19 silencing suppressor was tested for enhanced RiZS1 expression. Bacterial suspensions carrying p19 and RiZS1 were applied together by mixing the suspensions either by adding both in equal amounts (1:1 v:v) or adding one fifth of p19 (1:4 v:v). Each infiltration culture was applied to five different leaves at $1 \mathrm{ml}$ total volume per leaf. After infiltration, the leaves were blotted dry with paper tissue and the plants were transferred back to the greenhouse. Sampling was performed after incubation for 6 days. Altogether 20 leaf disks $(15 \mathrm{~mm} \varnothing)$ per sample were collected and placed on a petri dish. Substrate (1 mM 4-OHBA)

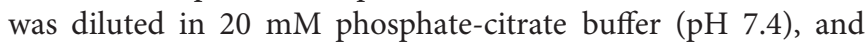
petri dishes were subjected to vacuum conditions twice. After 2 days of incubation, the samples were frozen in liquid nitrogen and stored at $-80^{\circ} \mathrm{C}$ until analyses. Each sample was taken in triplicate.

\section{Biotransformation}

Cell suspension cultures were inoculated for 5 days and hairy roots for 9 days prior to feeding, as described in Häkkinen et al. (2012). Precursor was diluted in sterile water and was fed at a final concentration of 100,300 , or $500 \mu \mathrm{M}$. Samples were collected after 1, 2, or 5 days and medium was separated from cells by filtering. Cell and medium samples were frozen and lyophilized before extraction.

\section{Sample Extraction and GC-MS Analyses}

Plant material was grinded with a Retsch mill (MM301, GWB, Germany) into a fine powder. Samples were weighed (50 mg lyophilized material) and $2 \mathrm{ml}$ ultra-pure water was added. Alternatively, $3 \mathrm{ml}$ medium samples were taken for the extraction and spiked with internal standard $(20 \mu \mathrm{g}$ heptadecanoic acid). Raspberry ketone was extracted twice with $5 \mathrm{ml}$ ethyl acetate in an ultrasonic bath $\left(10 \mathrm{~min},+25^{\circ} \mathrm{C}\right)$. The supernatants were separated and combined after centrifugation (3000 rpm, $10 \mathrm{~min}$ ) and evaporated to dryness under nitrogen flow. The residues were dissolved in dichloromethane $(50 \mu \mathrm{l}$; DCM) and trimethylsilylated with MSTFA (25 $\mu \mathrm{l} ; \mathrm{N}$-Methyl$N$-(trimethylsilyl) trifluoroacetamide; Pierce, Rockford, IL, USA) at $80^{\circ} \mathrm{C}$ for $20 \mathrm{~min}$. Deglycosylation was performed with plant material into citrate-phosphate buffer ( $\mathrm{pH}$ 5.4). After sonication (15 min), $500 \mu l$ Viscozyme L (V2010, Sigma-Aldrich, USA) was added and a heptane-layer together with internal standard was added on top of the solution. Samples were incubated at $+37^{\circ} \mathrm{C}$ overnight and the aqueous phase was extracted with ethyl acetate as described above. Medium samples were extracted accordingly.

The samples were analyzed with an Agilent 7890A GC combined with a 5975C mass selective detector. The GC was equipped with an Agilent DB-5MS fused silica capillary column ( $30 \mathrm{~m}, 0.25 \mathrm{~mm}$ ID, phase thickness of 0.25 ) and the temperature program was from $70^{\circ} \mathrm{C}(1 \mathrm{~min})$ to $280^{\circ} \mathrm{C}(18 \mathrm{~min})$ at $10^{\circ} \mathrm{C}$ $\min ^{-1}$. Aliquots of $1 \mu \mathrm{l}$ were injected and the split ratio was 25:1. The data were collected over a mass range of 40$600 \mathrm{~m} / \mathrm{z}$. Identification of the compounds was based on retention times and library comparison (NIST '08, Scientific Instrument Services, Inc., Ringoes, NJ, USA). Calibration curves of reference substances were used for quantification.

\section{RESULTS}

\section{Transient Expression of RiZS1 in N. benthamiana}

Transient expression in N. benthamiana was performed using A. tumefaciens LBA4404 carrying either the p19 silencing suppressor (Silhavy et al., 2002) or 35S-RiZS1, alone or in combination. Two different dilutions of silencing suppressor p19 were tested against 35S:RiZS1 since the concentration required for optimal suppression activity was not known. Bioconversion of $\mathbf{1}$ was assayed after incubating leaf samples for 2 days. Product 3 accumulation was observed in all samples which received substrate 1 (Figures 2A,B). Only those samples without added substrate were completely devoid of 3 . However, to our surprise, control samples, i.e., samples in which only p19 was infiltrated, also contained raspberry ketone in similar amounts to those observed in RiZS1 infiltrated samples. Furthermore, p19 did not 


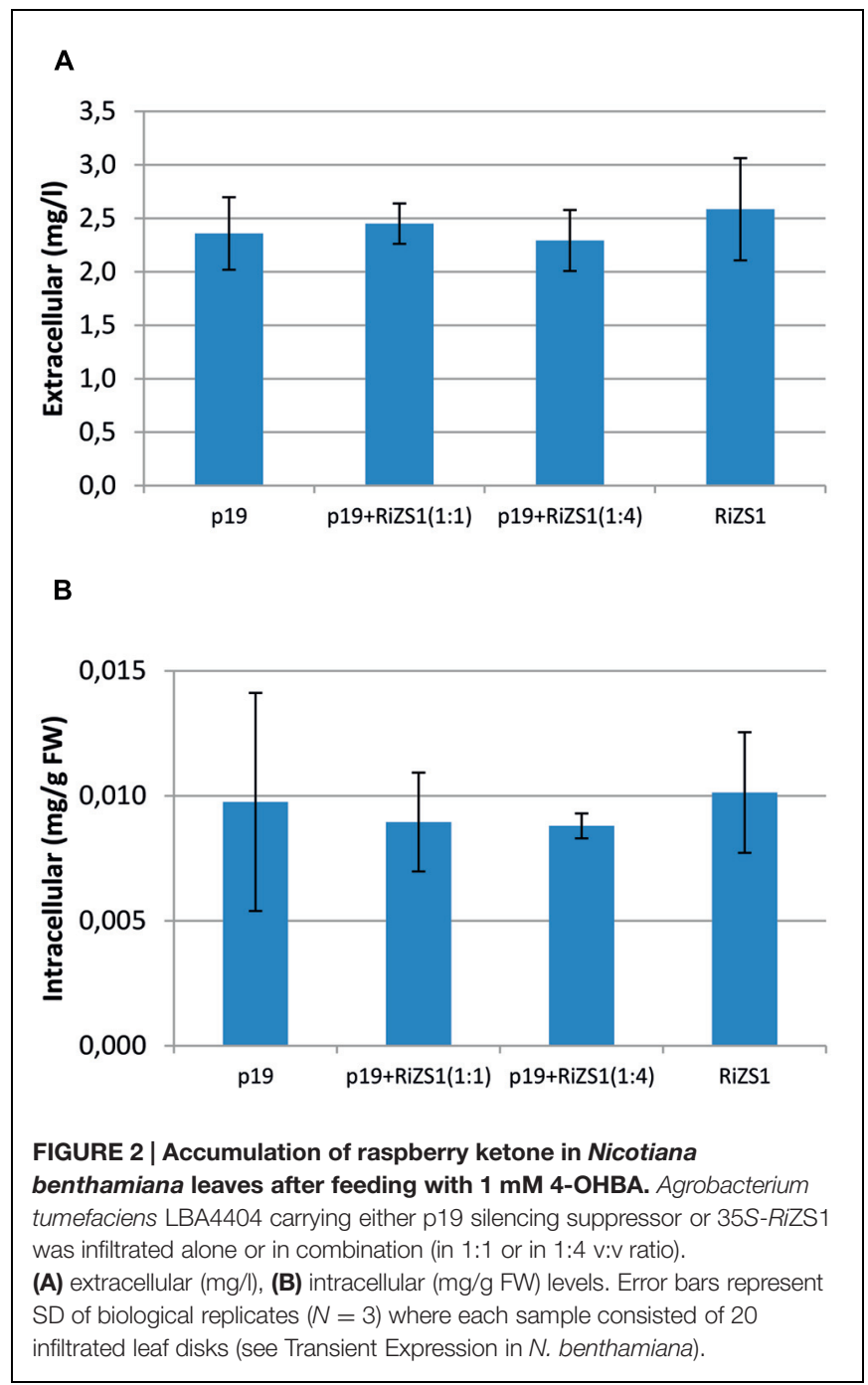

appear to have any effect on the raspberry ketone accumulation levels.

\section{Raspberry Ketone Production in Tobacco Hairy Roots}

The known 4-OHBA reductase RiZS1 was cloned in the Gateway ${ }^{\circledR}$ plant-compatible overexpression vector and introduced to $N$. tabacum by $A$. rhizogenes. Altogether ten $N$. tabacum hairy root clones were generated carrying RiZS1 and they were subsequently screened for raspberry ketone production capacity. Hairy roots were first pre-cultivated for 9 days as described in Häkkinen et al. (2012) in order to increase the biomass as well as to reach the exponential growth phase for active intracellular metabolism. Raspberry ketone $\mathbf{3}$ was produced in three clones after feeding $\mathbf{1}$ and the best-producing clone was selected for further experiments. When hairy roots were fed with the substrate $\mathbf{1}$, the majority of the subsequently produced 3 was secreted to the extracellular space. The accumulation of 3 was monitored for 6 days and it showed that the accumulation peak of $\mathbf{3}$ occurred already at

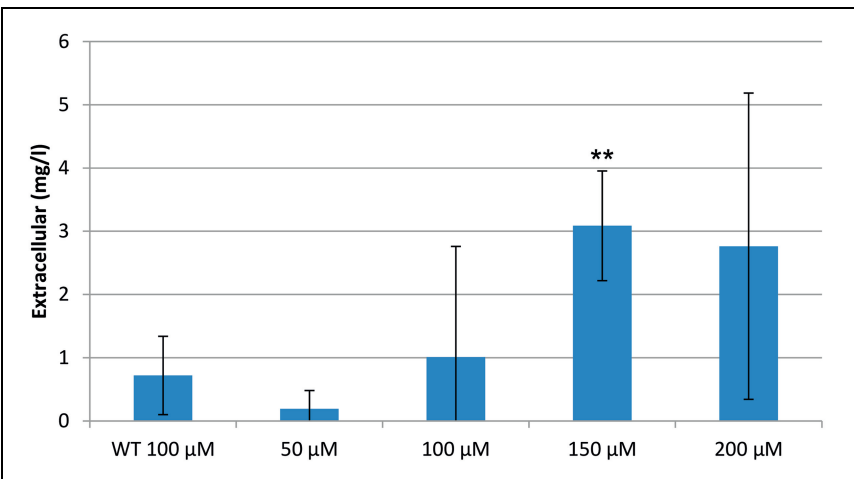

FIGURE 3 | Formation of raspberry ketone (mg/l) in the extracellular space of $N$. tabacum hairy roots expressing $35 S-R i Z S 1$ with different concentrations of fed 4-OHBA. Feeding was performed after 9 days of cultivation and samples were taken $1 \mathrm{~d}$ after feeding. Error bars represent the standard deviation of three biological replicates. The experiment was repeated twice. WT, wild type. Asterisks indicate the significance level obtained by Student's t-test: ${ }^{*} p<0.05,{ }^{* *} p<0.01,{ }^{* * *} p<0.001$.

day 1. Increased concentration of substrate resulted in an average $(N=3)$ of up to $3.0 \mathrm{mg} / \mathrm{l}$ raspberry ketone production from $150 \mu \mathrm{M} 1$ (Figure 3). A yield of up to $5.5 \mathrm{mg} / \mathrm{l}$ was obtained after feeding $200 \mu \mathrm{M}$, but the variation between the biological replicates was too high for reliable interpretation of the result.

In order to confirm the hypothesis drawn from the earlier $N$. benthamiana experiment, wild type (WT) hairy roots were also tested for their bioconversion capacity of $\mathbf{1}$. We did indeed find that WT roots converted 1-3 at similar conversion rates as roots carrying RiZS1 (Figure 3). However, only three out of ten roots carrying RiZS1 produced 3 after feeding. The majority of produced 3 was secreted to the culture medium; only up to $0.2 \%$ of the whole raspberry ketone pool was found in the intracellular fraction. Fed $\mathbf{1}$ did not show spontaneous conversion into 3 during the experimental time period as tested by cell-free incubation of substrate in the medium. Furthermore, the majority of produced raspberry ketone in tobacco hairy roots was present as aglycone both in the intra- and the extracellular samples.

Hairy roots were also pre-cultivated for 21 days before feeding with $\mathbf{1}$, in order to confirm the optimal growth phase for starting the feeding. However, raspberry ketone was not produced at all in these hairy roots, which had reached the stationary growth phase, thus confirming the necessity for rapidly dividing cells and high overall enzymatic activity during feeding.

In order to study whether elicitation could result in increased bioconversion yields in tobacco hairy roots, methyl jasmonate (MeJA) was applied simultaneously with the substrate. However, it was observed that elicitation with MeJA did not increase the amount of raspberry ketone produced (Supplementary Table S1).

\section{Bioconversion of Betuligenol and 4-OHBA by Various Plant Cell Suspensions and Hairy Root Cultures}

To test the hypothesis of widely distributed plant reductase activity which is able to accept and convert raspberry ketone precursors, we screened several plant cell cultures for their 
TABLE 1 | Amount of raspberry ketone produced by selected cell suspensions and hairy root cultures 1 day after feeding with $100 \mu$ M 4-OHBA or betuligenol, respectively.

\begin{tabular}{|c|c|c|c|c|c|c|}
\hline \multirow[t]{3}{*}{ Family } & \multirow[t]{3}{*}{ Species } & \multirow[t]{3}{*}{ Culture type } & \multicolumn{4}{|c|}{ Raspberry ketone } \\
\hline & & & \multicolumn{2}{|c|}{ 4-ОНBA (1) } & \multicolumn{2}{|c|}{ Betuligenol (2) } \\
\hline & & & $\begin{array}{c}\text { Cells } \\
(\mu \mathrm{g} / \mathrm{g} \mathrm{DW})\end{array}$ & $\begin{array}{c}\text { Medium } \\
(\mathrm{mg} / \mathrm{l})\end{array}$ & $\begin{array}{c}\text { Cells } \\
(\mu \mathrm{g} / \mathrm{g} \mathrm{DW})\end{array}$ & $\begin{array}{c}\text { Medium } \\
\text { (mg/l) }\end{array}$ \\
\hline Apocynaceae & Catharanthus roseus & Cell suspension & ND & ND & ND & ND \\
\hline Apocynaceae & Catharanthus roseus & Hairy root & 29.0 & 1.3 & 4.1 & 0.1 \\
\hline Plumbaginaceae & Plumbago auriculata & Cell suspension & 0.6 & ND & 15.9 & $\operatorname{tr}$ \\
\hline Poaceae & Hordeum vulgare & Cell suspension & 6.0 & $\operatorname{tr}$ & $\operatorname{tr}$ & $\operatorname{tr}$ \\
\hline Rosaceae & Rubus arcticus & Cell suspension & 6.4 & ND & $\operatorname{tr}$ & ND \\
\hline Rosaceae & Rubus chamaemorus** & Cell suspension & 8.0 & 2.1 & 10.8 & 0.4 \\
\hline Rosaceae & Rubus idaeus** & Cell suspension & 11.1 & 0.1 & ND & ND \\
\hline Solanaceae & N. tabacum SR1 & Cell suspension & 2.6 & 0.1 & $\operatorname{tr}$ & 0.2 \\
\hline Solanaceae & N. tabacum SR1 & Hairy root & $6.0^{*}$ & $0.7^{*}$ & 3.0 & ND \\
\hline Solanaceae & Hyoscyamus muticus & Hairy root & 2.0 & ND & ND & ND \\
\hline
\end{tabular}

ND, not detected; tr, trace, $<0.05$ ppm. *Mean calculated from six individual clones (2.3-12.0 ug/g DW and 0.1-1.8 mg/l). **freshly prepared suspensions from calli.

TABLE 2 | Bioconversion of $500 \mu$ M 4-OHBA and betuligenol by plant cell suspension cultures 1 day after feeding, unless otherwise indicated.

\begin{tabular}{|c|c|c|c|c|c|c|c|}
\hline \multirow[t]{3}{*}{ Family } & \multirow[t]{3}{*}{ Species } & \multicolumn{6}{|c|}{ Raspberry ketone } \\
\hline & & \multicolumn{3}{|c|}{ 4-ОНВA (1) } & \multicolumn{3}{|c|}{ Betuligenol (2) } \\
\hline & & $\begin{array}{c}\text { Cells } \\
(\mu \mathrm{g} / \mathrm{g} \text { DW })\end{array}$ & $\begin{array}{c}\text { Medium } \\
(\mathrm{mg} / \mathrm{l})\end{array}$ & $\begin{array}{l}\% \text { in culture } \\
\text { medium }\end{array}$ & $\begin{array}{c}\text { Cells } \\
(\mu \mathrm{g} / \mathrm{g} \mathrm{DW})\end{array}$ & $\begin{array}{l}\text { Medium } \\
(\mathrm{mg} / \mathrm{l})\end{array}$ & $\begin{array}{c}\% \text { in culture } \\
\text { medium }\end{array}$ \\
\hline Ericaceae & Vaccinium myrtillus & ND & ND & 0 & ND & ND & 0 \\
\hline Poaceae & Hordeum vulgare* & 1.0 & $\operatorname{tr}$ & 78 & 0.3 & ND & 0 \\
\hline Rosaceae & Rubus arcticus* & 12.0 & ND & 0 & 2.6 & ND & 0 \\
\hline Rosaceae & $\begin{array}{l}\text { Rubus } \\
\text { chamaemorus }\end{array}$ & 29.1 & 0.6 & 75 & 20.5 & 1.1 & 88 \\
\hline Rosaceae & Rubus idaeus & 80.2 & 1.9 & 81 & 2.2 & 0.2 & 94 \\
\hline Solanaceae & N. tabacum BY-2 & 158.2 & 7.4 & 75 & 106.3 & 5.0 & 75 \\
\hline
\end{tabular}

*sample taken after 5 days; ND, not detected; tr, trace, $<0.05$ ppm.

bioconversion capacity. Altogether seven undifferentiated and three differentiated cell cultures from five different plant families were tested (Table 1). It was clearly observed that the majority of cultures were able to convert either one or both of the tested substrates into raspberry ketone. Since most of the produced 3 was found in the culture medium, the best converters were cloudberry suspension and C. roseus and $N$. tabacum hairy roots (Table 1). In this list, C. roseus cell suspension was the only culture which did not show conversion of either substrate.

After the initial screening, more detailed bioconversion studies were conducted with selected suspension cultures. Altogether six cell suspension cultures, four included in the first screening (barley, cloudberry, arctic bramble, raspberry) plus bilberry and tobacco BY-2, were subjected to further studies, including the testing of different substrate concentrations and sampling points.

Among all six cell suspensions only bilberry did not convert either $\mathbf{1}$ or $\mathbf{2}$. Increasing levels of substrate resulted in close to dose-dependent accumulation of $\mathbf{3}$ in all other cultures tested, except for barley and arctic bramble (Table 2).
The three tested Rubus species showed rather different patterns of accumulation of $\mathbf{3}$. Cloudberry converted both $\mathbf{1}$ and $\mathbf{2}$ at almost equal rates; raspberry showed a preference for $\mathbf{1}$ and arctic bramble was able to convert both substrates; however, the product accumulated only in the intracellular space (Table 2). Based on the earlier reports of a hydrogen acceptor requirement during betuligenol bioconversion, acetone was added to the incubation mixture of hairy roots used in this study. However, this did not result in increased production of $\mathbf{3}$ (Supplementary Table S2). Among the cultures tested in this study, C. roseus and $V$. myrtillus cell suspension cultures did not produce 3 (Tables 1 and 2).

By far the best conversion of both $\mathbf{1}$ and $\mathbf{2 - 3}$ was achieved with N. tabacum BY-2, raspberry and cloudberry cells (Table 2), with tobacco BY-2 showing up to $12 \%$ total conversion rate. All the cultures tested, except arctic bramble, accumulated more than $75 \%$ of the product in the culture medium (Table 2).

The temporal accumulation pattern observed for N. tabacum BY-2 (Figure 4) shows that the highest amount of $\mathbf{3}$ accumulated both in the intra- and extracellular space 1 day after substrate 


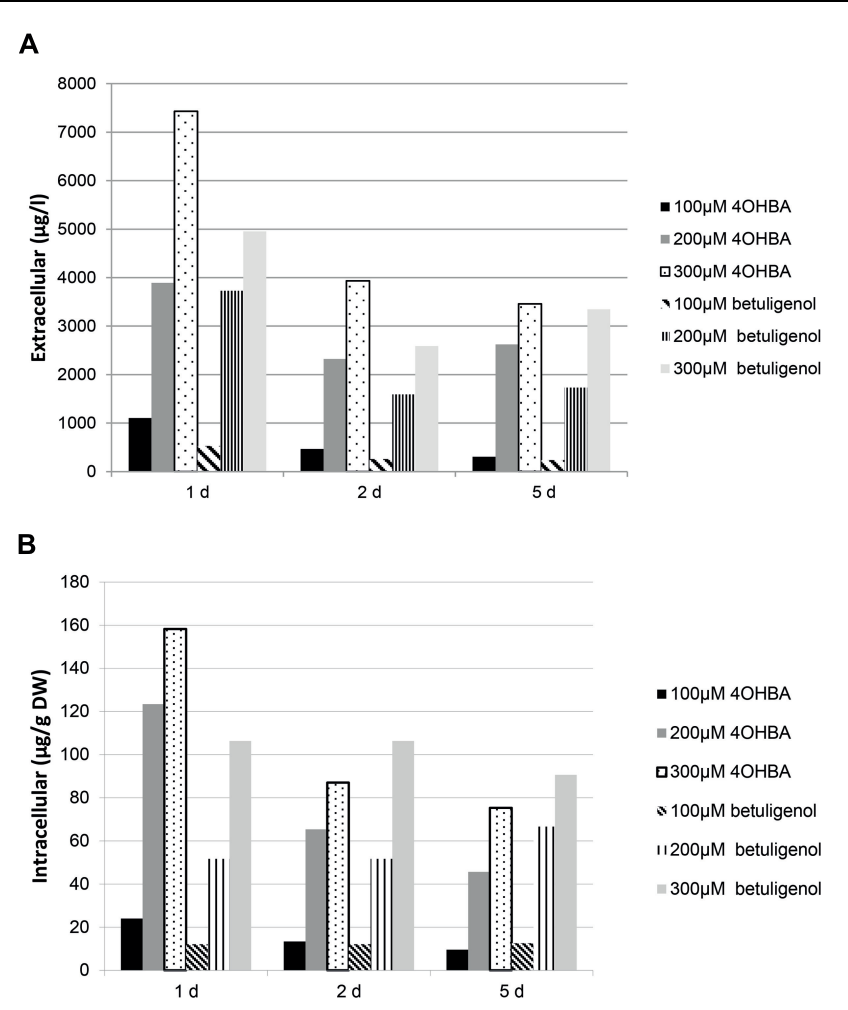

FIGURE 4 | Accumulation of raspberry ketone in culture medium $(\mu \mathrm{g} / \mathrm{l})$ (A) and in intracellular space ( $\mu \mathrm{g} / \mathrm{g}$ DW) (B) in N. tabacum BY-2 cell suspension culture after feeding with either 4-OHBA or betuligenol.

feeding. After 1 day the level of $\mathbf{3}$ declined, possibly due to degradation or further metabolism. In the case of barley and arctic bramble the highest accumulation of $\mathbf{3}$ occurred only after 5 days. Tyrosol, a suggested metabolite resulting from degradation of $\mathbf{3}$, was not detected in cell culture samples tested in this study, based on the mass fragmentation patterns reported by Angerosa et al. (1995).

\section{DISCUSSION}

\section{Tobacco as a Production Platform for Raspberry Ketone}

As expected, $N$. benthamiana did not accumulate 3 without added substrate, since tobacco is not known to possess the whole pathway leading to raspberry ketone. However, to our surprise, 3 also accumulated in p19 infiltrated control samples in amounts similar to those in RiZS1 infiltrated samples. Similarly, in N. tabacum hairy root cultures, extracellular concentration of converted 3 was similar in WT hairy roots $(2.8 \mathrm{mg} / \mathrm{l})$ and hairy roots carrying RiZS1 (3.0 mg/l) (Figure 3; Table 1). RiZS1 belongs to the medium chain reductase/dehydrogenase (MDR)/zinc-dependent ADH-like family of proteins, a diverse group of proteins related to class I mammalian ADH. MDR proteins constitute a large enzyme superfamily with close to 1000 members (Nordling et al., 2002), and display a wide variety of activities including $\mathrm{ADH}$, quinone reductase, cinnamyl reductase and numerous others. It is interesting to note that the protein sequence of RiZS1 exhibits $76 \%$ similarity and $74 \%$ nucleotide sequence similarity with $N$. tabacum allyl ADH (DDBJ/EMBL/GenBank accession nr. AB036735) (Supplementary Figure S1).

This tobacco gene was later renamed as NtDBR (N. tabacum

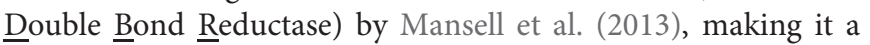
prime candidate responsible for the observed activities in WT $N$. benthamiana and $N$. tabacum hairy roots. NtDBR has $70 \%$ homology to the NADPH-dependent oxidoreductases belonging to a plant $\zeta$-crystallin family [leukotriene B4 dehydrogenase family (LTD), a subfamily of the MDR superfamily proteins] and it catalyzes a reversible dehydrogenation of allylic alcohols or ketones (Hirata et al., 2000). Both RiZS1 and NtDBR belong to the LTD family and both have an NADPH co-factor binding site AXXGXXG.

The accumulation peak of 3 in tobacco hairy roots and cell suspensions, as well as in most other cultures tested, was observed already at day 1 (Figure 4). This is in accordance with the results obtained with A. belladonna by Srivastava et al. (2013), i.e., bioconversion taking place already at day 1 although the maximum conversion was obtained at day 5 . Since only three out of ten roots carrying RiZS1 actually produced 3 after feeding, it is suspected that co-supression (Vaucheret and Fagard, 2001) occurred in the remaining transgenic clones, resulting most probably from a high sequence similarity between RiZS1 and corresponding endogenous reductases (Supplementary Figure $\mathrm{S} 1$ ). Production levels up to $5.5 \mathrm{mg} / \mathrm{l}$ of 3 were recorded for hairy roots after feeding $200 \mu \mathrm{M}$ of $\mathbf{1}$. These levels correspond to those reported by Beekwilder et al. (2007) with $5 \mathrm{mg} / \mathrm{l}$ production rates obtained by $E$. coli expressing chalcone synthase from Rubus idaeus. In fresh raspberry fruits, levels of $0.01-0.17 \mu \mathrm{g} / \mathrm{g}$ have been reported (Hrazdina and Zheng, 2006). Accumulation levels up to $20 \mu \mathrm{g} / \mathrm{g}$ have been obtained in elicited raspberry cell cultures (Hrazdina and Zheng, 2006).

Glycosylation is a very important detoxification mechanism in xenobiotic metabolism (Schmidt et al., 2006; Häkkinen et al., 2012). In addition, glycosylation facilitates the conversion of water-insoluble substances into water-soluble compounds and may also be needed in aiding the transport of the particular compound to e.g., vacuole or apoplastic space. Particularly, glycosylation by cultured plant cells has been the subject of increasing attention, since one-step enzymatic glycosylations by plant cells are more convenient than chemical glycosylations, which require tedious steps of protection and deprotection of the sugar hydroxyl groups. For this reason possible glycosylated conjugates of raspberry ketone were screened following enzyme-assisted deglycosylation. However, the main part of $\mathbf{3}$ was present as aglycone in tobacco hairy roots. Glycosylation of fed raspberry ketone was earlier demonstrated by Shimoda et al. (2007) with cultured cells of Phytolacca americana, which converted fed raspberry ketone into $\beta$-glycosides after hydroxylation during a 3 day incubation period.

Altogether, the conversion efficiency of hairy roots was much higher than that of infiltrated leaves, $12 \%$ versus $2 \%$, respectively. 
The difference is even more striking if the incubation time is taken into account, since hairy roots were sampled after 1 day and infiltrated leaves after 2 days. It is noteworthy that the bioconversion yield obtained in this study with $N$. tabacum hairy roots is higher than the bioconversion of betuligenol reported by Srivastava et al. (2013), who obtained an overall $0.5 \%$ bioconversion rate at day 1 and a maximum of $7 \%$ bioconversion after 5 days with A. belladonna hairy roots (calculated from the presented data). The microbial bioconversion capacity of E. coli converting 1-3 was reported as $40 \%$ after 1 day by Beekwilder et al. (2007), whereas bioconversion of 2-3 using Rhodococcus cells in buffer with $10 \%(\mathrm{v} / \mathrm{v})$ acetone was as high as $89 \%$ after 2 days (Kosjek et al., 2003). As a conclusion, although unable to compete with microbial bioconversion systems in terms of yield, N. tabacum hairy roots offer an efficient plantbased bioconversion platform for production of natural raspberry ketone.

\section{Betuligenol and 4-OHBA are Converted to Raspberry Ketone by Various Plant Species \\ Hairy Roots}

Bioconversion capacity differed even between closely related plant species, e.g., the two Solanaceae. Whereas N. tabacum hairy roots were able to convert betuligenol, the related $H$. muticus did not show bioconversion. Earlier, Srivastava et al. (2013) reported that hairy roots of another Solanaceae, A. belladonna, were able to convert 2 to raspberry ketone. Since Kosjek et al. (2003) had reported from work with bacterial cultures that $\mathbf{2}$ would require acetone as a hydrogen acceptor, hairy roots were fed with betuligenol together with acetone at a concentration of $1 \%(\mathrm{v} / \mathrm{v})$. However, the efficiency of bioconversion was not improved by acetone addition. This is in accordance with reported betuligenol bioconversion in A. belladonna, which performed the bioconversion as such (Srivastava et al., 2013). This difference between prokaryotic and plant platforms may be explained by the differences in oxidative enzymes. Plants possess a huge variety of cytochrome P450 enzymes together with an abundant hydrogen acceptor pool, carrying out diverse oxidative reactions, whereas the number of $\mathrm{P} 450$ enzymes in prokaryotes is generally much lower, and E. coli does not possess any at all (Werck-Reichhart and Feyereisen, 2000).

\section{Cell Suspensions}

Tobacco BY-2 performed best in this study, with $12 \%$ total conversion rate, which is higher than the earlier reported plantbased conversion by A. belladonna hairy roots (7\%, Srivastava et al., 2013). Rubus sp., namely raspberry and cloudberry constitute further potent plant platforms (Table 2). The cell density of highly multiplying BY-2 culture is high during the exponential growth phase. However, the total amount of biomass at the time of sampling in tobacco BY-2 was approximately twofold compared to other cultures tested. Thus, the number of cells performing the bioconversion cannot be the only reason for the high bioconversion rates in tobacco BY-2. It should also be noted that different cell cultures might possess different optimal growth stages for specific bioconversions, and thus accurate comparisons of the bioconversion potential of different cultures cannot be made without more detailed studies.

Accumulation in culture medium, as seen in all the cultures tested except for arctic bramble, is a highly appreciated phenomenon compared to the typical intracellular location of secondary metabolites. Although product degradation may occur as a function of time (Figure 4), by timing the product recovery correctly the yields of produced 3 remain rather high. Earlier it had been suggested that raspberry ketone is degraded into tyrosol in fungi (Fuganti et al., 1996), but tyrosol was not detected in our cell culture samples.

The demand for "natural" raspberry ketone is growing considerably, partly due to the recent findings related to its favorable properties related to weight regulation and skinlightening (Morimoto et al., 2005; Park, 2010; Lin et al., 2011). Bioconversion is an efficient and 'green' technology to convert various substrates into more valuable or less toxic compounds. In this work we have shown that a wide variety of plant cell cultures can be utilized for bioconversion purposes, allowing production in a contained environment, independent of environmental conditions and free of pesticides and contaminants. In the case of raspberry ketone, a very high-value natural flavor substance can be produced in plant cell cultures by applying 4hydroxybenzalacetone or betuligenol, both of which are rather cheap and readily available precursors. Accumulation in the extracellular space, as shown in this study, is beneficial for compound recovery. Downstream processing may account for as much as $80 \%$ of overall production costs and for this reason less complex compound isolation and purification from the culture medium has a major impact on the total costs of a biotechnological process.

\section{AUTHOR CONTRIBUTIONS}

SH, TS-L, K-MO-C, HR designed the research; SH and TS-L performed the research; SH, TS-L, HR analyzed data; SH, HR wrote the paper.

\section{ACKNOWLEDGMENTS}

We thank Airi Hyrkäs, Jaana Rikkinen, and Anna-Liisa Ruskeepää for excellent technical assistance. This work was supported by the Academy of Finland (grant 138808 to HR) and VTT. The authors acknowledge the support of COST Action FA1006 PlantEngine.

\section{SUPPLEMENTARY MATERIAL}

The Supplementary Material for this article can be found online at: http://journal.frontiersin.org/article/10.3389/fpls.2015.01035 


\section{REFERENCES}

Abe, I., Takahashi, Y., Morita, H., and Noguchi, H. (2001). Benzalacetone synthase. A novel polyketide synthase that plays a crucial role in the biosynthesis of phenylbutanones in Rheum palmatum. Eur. J. Biochem. 268, 3354-3359. doi: 10.1046/j.1432-1327.2001.02255.x

Angerosa, F., d'Alessandro, N., Konstantinou, P., and Di Giacinto, L. (1995). GCMS evaluation of phenolic compounds in virgin olive oil. J. Agric. Food Chem. 43, 1802-1807. doi: 10.1021/jf00055a010

Beekwilder, J., van der Meer, I. M., Sibbesen, O., Broekgaarden, M., Qvist, I., Mikkelsen, J. D., et al. (2007). Microbial production of natural raspberry ketone. Biotechnol. J. 2, 1270-1279. doi: 10.1002/biot.200 700076

Chattopadhyay, S. K., Sharma, R. P., and Kumar, S. (2001). Process for the Production of 4-aryl-2-Butanols from Taxus wallichiana. US Patent 6184367.

Dumont, B., Hugueny, P., and Belin, J. M. (1996). Production Par Bioconversion de Cétone Framboise. European Patent EP 0, 072A1.

Feron, G., Mauvais, G., Martin, F., Sémon, E., and Blin-Perrin, C. (2007). Microbial production of 4-hydroxybenzylidene acetone, the direct precursor of raspberry ketone. Lett. Appl. Microbiol. 45, 29-35. doi: 10.1111/j.1472-765X.2007.0 2147.x

Feron, G., and Wache, Y. (2005). "Microbial production of food flavour," in Food Biotech, eds K. Shetty, A. L. Pometto, and G. Paliyath (New York, NY: M. Dekker Inc.), 408-441.

Fischer, M., Böker, A., and Berger, R. G. (2001). Fungal formation of raspberry ketone differs from the pathway in plant cell culture. Food Biotechnol. 15, 147-155. doi: 10.1081/FBT-100107626

Fuganti, C., Mendozza, M., Joulain, D., Minut, J., Pedrocchi-Fantoni, G., Piergianni, V., et al. (1996). Biogeneration and biodegradation of raspberry ketone in the fungus Beauveria bassiana. J. Agric. Food Chem. 44, 3616-3619. doi: $10.1021 /$ jf9508054

Fuganti, C., and Zucchi, G. (1998). Product distribution in the microbial biogeneration of raspberry ketone from 4-hydroxybenzalacetone. J. Mol. Catal. B Enzym. 4, 289-293. doi: 10.1016/S1381-1177(98)00008-3

Fujita, T., Hatamoto, H., Miyamoto, M., Iwasaki, T., and Takafuji, S. (1998). Rhododendrol biosynthesis and metabolism in Acer nikoense callus. Biotechnol. Lett. 20, 1057-1061. doi: 10.1023/A:1005463123118

Giri, A., Dhingra, V., Giri, C. C., Singh, A., Ward, O. P., and Lakshmi Narasu, M. (2001). Biotransformations using plant cells, organ cultures and enzyme systems: current trends and future prospects. Biotechnol. Adv. 19, 175-199. doi: 10.1016/S0734-9750(01)00054-4

Häkkinen, S. T., Lackman, P., Nygrén, H., Oksman-Caldentey, K.-M., Maaheimo, H., and Rischer, H. (2012). Differential patterns of dehydroabietic acid biotransformation by Nicotiana tabacum and Catharanthus roseus cells. J. Biotechnol. 157, 287-294. doi: 10.1016/j.jbiotec.2011. 11.008

Häkkinen, S. T., Moyano, E., Cusidó, R. M., Palazón, J., Piñol, M. T., and OksmanCaldentey, K.-M. (2005). Enhanced secretion of tropane alkaloids in Nicotiana tabacum hairy roots expressing heterologous hyoscyamine-6 $\beta$-hydroxylase. J. Exp. Bot. 56, 2611-2618. doi: 10.1093/jxb/eri253

Hirata, T., Tamura, Y., Yokobatake, Y. N., Shimoda, K., and Ashida, Y. (2000). A $38 \mathrm{kDa}$ allylic alcohol dehydrogenase from the cultured cells of Nicotiana tabacum. Phytochemistry 55, 297-303. doi: 10.1016/S0031-9422(00)0 0326-5

Hrazdina, G., and Zheng, D. (2006). "Expression and function of aromatic polyketide synthase genes in raspberries (Rubus idaeus sp.)," in Polyketides: Biosynthesis, Biological Activities and Genetic Engineering, eds A. M. Rimando and S. R. Baerson (Washington, D.C: American Chemical Society), $128-140$.

Ishihara, K., Hamada, H., Hirata, T., and Nakajima, N. (2003). Biotransformation using plant cultured cells. J. Mol. Catal. B Enzym. 23, 145-170. doi: 10.1016/S1381-1177(03)00080-8

Joensuu, J. J., Conley, A. J., Lienemann, M., Brandle, J. E., Linder, M. B., and Menassa, R. (2010). Hydrophobin fusions for high-level transient protein expression and purification in Nicotiana benthamiana. Plant Physiol. 152, 622-633. doi: 10.1104/pp.109.149021

Koeduka, T., Watanabe, B., Suzuki, S., Hiratake, J., Mano, J., and Yazaki, K. (2011). Characterization of raspberry ketone/zingerone synthase, catalyzing the alpha, beta-hydrogenation of phenylbutenones in raspberry fruits. Biochem. Biophys. Res. Commun. 412, 104-108. doi: 10.1016/j.bbrc.2011. 07.052

Kosjek, B., Stampfer, W., van Deursen, R., Faber, K., and Kroutil, W. (2003). Efficient production of raspberry ketone via 'green' biocatalytic oxidation. Tetrahedron 59, 9517-9521. doi: 10.1016/j.tet.2003.1 0.019

Lin, C.-H., Lin, V., Ding, H.-Y., Kuo, S.-Y., Chin, L.-W., Wu, J.-Y., et al. (2011). Evaluation of in Vitro and in Vivo depigmenting activity of raspberry ketone from Rheum officinale. Int. J. Mol. Sci. 12, 4819-4835. doi: $10.3390 /$ ijms 12084819

Mansell, D. J., Toogood, H. S., Waller, J., Hughes, J. M. X., Levy, C. W., Gardiner, J. M., et al. (2013). Biocatalytic asymmetric alkene reduction: crystal structure and characterization of a double bond reductase from Nicotiana tabacum. ACS Catalysis 3, 370-379. doi: 10.1021/cs $300709 \mathrm{~m}$

McCown, B. H., and Lloyd, G. (1981). Woody Plant Medium (WPM) - a mineral nutrient formulation for microculture for woody plant species. Hortic. Sci. $16: 453$.

Morimoto, C., Satoh, Y., Harab, M., Inoue, S., Tsujitae, T., and Okuda, H. (2005). Anti-obese action of raspberry ketone. Life Sci. 77, 194-204. doi: 10.1016/j.lfs.2004.12.029

Murashige, T., and Skoog, F. (1962). A revised medium for rapid growth and bioassays with tobacco tissue cultures. Physiol. Plant. 15, 473-497. doi: 10.1111/j.1399-3054.1962.tb08052.x

Nohynek, L., Bailey, M., Tähtiharju, J., Seppänen-Laakso, T., Rischer, H., Oksman-Caldentey, K.-M., et al. (2014). Cloudberry (Rubus chamaemorus) cell culture with bioactive substances: establishment and mass propagation for industrial use. Eng. Life Sci. 14, 667-675. doi: 10.1002/elsc.201 400069

Nordling, E., Jörnvall, H., and Persson, B. (2002). Medium-chain dehydrogenases/reductases (MDR). Eur. J. Biochem. 269, 4267-4276. doi: 10.1046/j.1432-1033.2002.03114.x

Park, K. S. (2010). Raspberry ketone increases both lipolysis and fatty acid oxidation in 3T3-L1 adipocytes. Planta Med. 76, 1654-1658. doi: 10.1055/s0030-1249860

Ritala, A., Mannonen, L., Aspegren, K., Salmenkallio-Marttila, M., Kurtén, U., Hannus, R., et al. (1993). Stable transformation of barley tissue culture by particle bombardment. Plant Cell Rep. 12, 435-440. doi: 10.1007/BF00 234708

Schmidt, B., Joussen, N., Bode, M., and Schuphan, I. (2006). Oxidative metabolic profiling of xenobiotics by human P450s expressed in tobacco cell suspension cultures. Biochem. Soc. Trans. 34, 1241-1245. doi: 10.1042/BST0 341241

Shimoda, K., Harada, T., Hamada, H., Nakajima, N., and Hamada, H. (2007). Biotransformation of raspberry ketone and zingerone by cultured cells of Phytolacca americana. Phytochemistry 68, 487-492. doi: 10.1016/j.phytochem.2006.11.030

Silhavy, D., Molnár, A., Lucioli, A., Szittya, G., Hornyik, C., Tavazza, M., et al. (2002). A viral protein suppresses RNA silencing and binds silencing-generated, 21- to 25-nucleotide double-stranded RNAs. EMBO J. 17, 3070-3080. doi: 10.1093/emboj/cdf312

Srivastava, V., Kaur, R., Chattopadhyay, S. K., and Banerjee, S. (2013). Production of industrially important cosmaceutical and pharmaceutical derivatives of betuligenol by Atropa belladonna hairy root mediated biotransformation. Ind. Crops Prod. 44, 171-175. doi: 10.1016/j.indcrop.2012. 11.016

Thompson, J. D., Higgins, D. G., and Gibson, T. J. (1994). CLUSTAL $\mathrm{W}$ : improving the sensitivity of progressive multiple sequence alignment through sequence weighting, positions-specific gap penalties and weight matrix choise. Nucleic Acid Res. 22, 4673-4680. doi: 10.1093/nar/22. 22.4673

Vandamme, E. J., and Soetaert, W. (2007). Bioflavours and fragrances via fermentation and biocatalysis. J. Chem. Technol. Biotechnol. 77, 1323-1332. doi: 10.1002/jctb.722

Vaucheret, H., and Fagard, M. (2001). Transcriptional gene silencing in plants: targets, inducers and regulators. Trends Genet. 17, 29-35. doi: 10.1016/S01689525(00)02166-1 
Werck-Reichhart, D., and Feyereisen, R. (2000). Cytochromes P450: a success story. Genome Biol. 1:REVIEWS3003. doi: 10.1186/gb-2000-1-6reviews 3003

Zheng, D., and Hrazdina, G. (2008). Molecular and biochemical characterization of benzalacetone synthase and chalcone synthase genes and their proteins from raspberry (Rubus idaeus L). Arch. Biochem. Biophys. 470, 139-145. doi: 10.1016/j.abb.2007.11.013

Zheng, D., Schröder, G., Schröder, J., and Hrazdina, G. (2001). Molecular and biochemical characterization of three aromatic polyketide synthase genes from Rubus idaeus. Plant Mol. Biol. 46, 1-15. doi: 10.1023/A:101064251 7738
Conflict of Interest Statement: The authors declare that the research was conducted in the absence of any commercial or financial relationships that could be construed as a potential conflict of interest.

Copyright (๑) 2015 Häkkinen, Seppänen-Laakso, Oksman-Caldentey and Rischer. This is an open-access article distributed under the terms of the Creative Commons Attribution License (CC BY). The use, distribution or reproduction in other forums is permitted, provided the original author(s) or licensor are credited and that the original publication in this journal is cited, in accordance with accepted academic practice. No use, distribution or reproduction is permitted which does not comply with these terms. 